\title{
Dataset of MIGRAME Project (Global Change, Altitudinal Range Shift and Colonization of Degraded Habitats in Mediterranean Mountains)
}

\author{
Antonio Jesús Pérez-Luque ${ }^{1,2}$, Regino Zamora ${ }^{1,2}$, \\ Francisco Javier Bonet ${ }^{1,2}$, Ramón Pérez-Pérez ${ }^{1,2}$
}

I Laboratorio de Ecologia (iEcolab), Instituto Interuniversitario de Investigación del Sistema Tierra en Andalucía (CEAMA), Universidad de Granada, Avenida del Mediterráneo s/n, 18006, Granada, Spain 2 Grupo de Ecología Terrestre, Departamento de Ecología, Universidad de Granada, Facultad de Ciencias, Campus de Fuentenueva s/n, 18071, Granada, Spain

Corresponding author: Antonio Jesús Pérez-Luque (ajperez@ugr.es)

Academic editor: L. Penev | Received 22 June 2015 | Accepted 18 September 2015 | Published 1 October 2015

Citation: Pérez-Luque AJ, Zamora R, Bonet FJ, Pérez-Pérez R (2015) Dataset of MIGRAME Project (Global Change, Altitudinal Range Shift and Colonization of Degraded Habitats in Mediterranean Mountains). PhytoKeys 56: 61-81. doi: $10.3897 /$ phytokeys. 56.5482

Resource citation: iEcolab, University of Granada-Andalusian Institute for Earth System Research (2015) Dataset of Global Change, altitudinal range shift and colonization of degraded habitats in Mediterranean mountains (MIGRAME). 3839 data records. Contributed by University of Granada, OBSNEV, Pérez-Luque AJ, Navarro-González I, Zamora R, Benito BM, Perez-Pérez R, Bonet FJ, Matías L, Ruiz-Puche R, Suzart F, Moreno-Llorca R, Rodríguez-Infante J. Online at http://www.gbif.es/ipt/resource.do?r=migrame and http://obsnev.es/noticia.html?id=7841, version 1.0 (last updated on 2015-05-13). Resource ID: GBIF Key: http://www.gbif.org/dataset/6c6a9003-ecea-4f3a-9f2f-414107da65c1

\begin{abstract}
In this data paper, we describe the dataset of the Global Change, Altitudinal Range Shift and Colonization of Degraded Habitats in Mediterranean Mountains (MIGRAME) project, which aims to assess the capacity of altitudinal migration and colonization of marginal habitats by Quercus pyrenaica Willd. for-
\end{abstract}

Copyright Antonio Jesús Pérez-Luque et al. This is an open access article distributed under the terms of the Creative Commons Attribution License (CC BY 4.0), which permits unrestricted use, distribution, and reproduction in any medium, provided the original author and source are credited. 
ests in Sierra Nevada (southern Spain) considering two global-change drivers: temperature increase and land-use changes. The dataset includes information of the forest structure (diameter size, tree height, and abundance) of the Quercus pyrenaica ecosystem in Sierra Nevada obtained from 199 transects sampled at the treeline ecotone, mature forest, and marginal habitats (abandoned cropland and pine plantations). A total of 3839 occurrence records were collected and 5751 measurements recorded. The dataset is included in the Sierra Nevada Global-Change Observatory (OBSNEV), a long-term research project designed to compile socio-ecological information on the major ecosystem types in order to identify the impacts of global change in this mountain range.

\section{Keywords}

Quercus pyrenaica forests, altitudinal migration, colonization of abandoned croplands, global change, Sierra Nevada (Spain), occurrence data, measurement data

\section{Project details}

Project title

Global Change, altitudinal range shift and colonization of degraded habitats in Mediterranean mountains (MIGRAME)

\section{Personnel}

Regino Jesús Zamora Rodríguez (Principal Investigator, University of Granada)

\section{Funding}

The project MIGRAME (RNM-6734) was funded by the Excellence Research Group Programme of the Andalusian Government (Spain).

\section{Rationale}

Currently, there is strong scientific evidence of the effects of global change on natural systems (Parmesan 2006, Rosenzweig et al. 2008, García et al. 2014, O’Connor et al. 2015). Some ecological processes are being altered due to the changing climate, such as species distribution (Thuiller et al. 2005, Lenoir et al. 2008), phenology (Parmesan and Yohe 2003, Gordo and Sanz 2010, Wolkovich et al. 2014), ecological interactions (Hughes 2000, Suttle et al. 2007); among others. Land-use changes and climate change are the most important drivers of biodiversity shifts (Sala et al. 2000). 
One of the most obvious biotic responses from global warming are the latitudinal and altitudinal shifts of species and communities (Allen and Breshears 1998, Jump and Peńuelas 2005, Lenoir et al. 2008). Species tend to expand into new areas that are becoming favourable, and retract from those that turn hostile. In consideration of two main drivers of global change (climatic warming and land abandonment), an understanding of the dynamics of altitudinal migration and colonization of marginal habitats is critical in order to develop effective forest-management strategies.

The project Global Change, altitudinal range shift, and colonization of degraded habitats in Mediterranean mountains (MIGRAME) was designed to assess the capacity of altitudinal migration and colonization of marginal habitats by a Mediterranean forest ecosystem (Zamora et al. 2013, Benito et al. 2013). This assessment considers two global change drivers: temperature increase and land-use changes. In so doing, this project analyzes the pattern of altitudinal migration and colonization of marginal habitats by a vulnerable ecosystem in a Mediterranean mountain region, which represents the rear edge of their distribution: forests of Quercus pyrenaica Willd.

The Mediterranean region has shown broad climate shifts in the past (Luterbacher et al. 2006) and is potentially vulnerable to forthcoming climatic changes (Pacifici et al. 2015), being considered a key region in future climate-change projections (Giorgi 2006, Giorgi and Lionello 2008). Concomitantly, land-use changes are considered a major driver of vegetation change (McGill 2015). This is especially relevant in Mediterranean region, which has undergone intense antrophic activities for millennia ( $\mathrm{Pa}-$ dilla et al. 2010) shaping the current landscape (Valbuena-Carabaña et al. 2010).

In this context, Mediterranean ecosystems are considered natural laboratories in which to study global change, due to their high sensitivity to global-change drivers (Matesanz and Valladares 2014, Doblas-Miranda et al. 2015).

\section{Study area descriptions/descriptor}

The target ecosystem of the project encompasses the Pyrenean oak forests (Quercus pyrenaica Willd.) of Sierra Nevada.

Sierra Nevada is a high-mountain range located in southern Spain $\left(37^{\circ} \mathrm{N}, 3^{\circ} \mathrm{W}\right)$ with altitudes of between $860 \mathrm{~m}$ and $3482 \mathrm{~m}$ a.s.l. The climate is Mediterranean, characterized by cold winters and hot summers, with pronounced summer drought (July-August). The Sierra Nevada mountain range hosts a high number of endemic plant species (c. 80) (Lorite et al. 2007) for a total of 2,100 species of vascular plants (25\% and 20\% of Spanish and European flora, respectively), and thus it is considered one of the most important biodiversity hotspots in the Mediterranean region (Blanca et al. 1998). This mountain area has 27 habitat types (listed in the European Union Habitat Directive) harbouring 31 animal species (20 birds, 5 mammals, 4 invertebrates, 2 amphibians and reptiles) and 20 plant species listed in the Annex I and II of EU Habitat and Bird Directives. Sierra Nevada has several types of legal protection: 
Biosphere Reserve MAB Committee UNESCO; Special Protection Area and Site of Community Importance (Natura 2000 network); and National Park. There are 61 municipalities with more than 90,000 inhabitants. The main economic activities are agriculture, tourism, beekeeping, mining, and skiing (Bonet et al. 2010).

For a description of the Pyrenean oak forests in Sierra Nevada, see Study extent description section.

\section{Design description}

The specific aims of the MIGRAME project are:

- To analyse the relevance of altitudinal migration at the leading edge (high elevation) of the range distribution of Pyrenean oak formation.

- To analyse the importance of the recolonization process of marginal habitats (abandoned croplands and pine plantations) close to Pyrenean oak formation.

Derived from the two global-change drivers, we have considered two main hypothesis (Figure 1):

\section{Altitudinal migration hypothesis}

Several studies have pointed out a trend towards higher temperatures and lower precipitation for the Mediterranean area (Giorgi and Lionello 2008, García-Ruiz et al. 2011). Climate projections forecast an increase of $+4.8^{\circ} \mathrm{C}$ at the end of the 21 st century (Benito et al. 2011) for Sierra Nevada. In this context, shifts in the altitudinal (and latitudinal) distribution of species and communities are expected (Thuiller et al. 2008, Gottfried et al. 2012).

We hypothesised that the range shift of $Q$. pyrenaica in Sierra Nevada is changing as a consequence of recent changes to temperature, and we would expect an upward expansion (Figure 1a).

\section{Marginal habitat colonization hypothesis}

In Mediterranean area, cropland abandonment has been widespread during the second half of the last century (Valbuena-Carabaña et al. 2010, Pías et al. 2014). Land-use change models predict an increase in this trend in the future (Rounsevell et al. 2006). In fact, land abandonment is considered one of the most powerful global-change drivers in developed countries (Escribano-Avila et al. 2012).

We hypothesised that the land-use changes in high mountain (e.g. abandonment of croplands, management of pine plantations) should facilitate the native forest regeneration, and a process of colonization of marginal habitat (abandoned cropland, pine plantations) will occur (Figure 1b). 

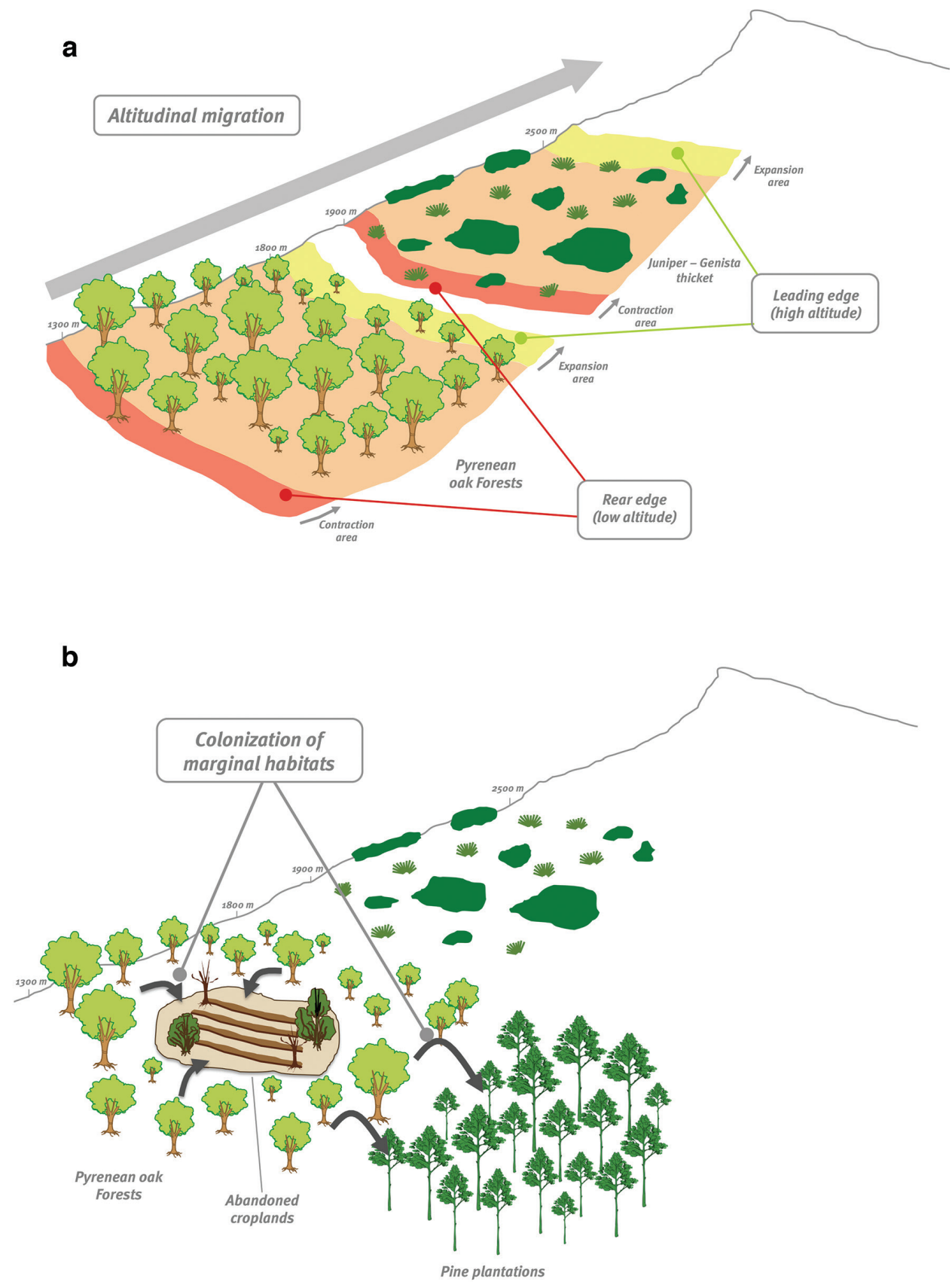

Figure I. Schematic representation of the two main hypothesis of the project: altitudinal migration (a) and colonization of marginal areas (b) of $Q$. pyrenaica forests. 
Overall, focusing on changes will occur in altitudinal migration and/or colonization of marginal habitats, we examine the following questions: Are altitudinal changes in Pyrenean oak forests associated with recent climate changes? Are they more consistent with changes in land use, or are they consistent with both global-change drivers?

\section{Data published through GBIF}

http://www.gbif.es/ipt/resource.do?r=migrame

\section{Taxonomic coverage}

This dataset includes records of the phylum Magnoliophyta (3823 records, 99.58\%) and marginally Pinophyta (16 records, below $1 \%$ of total records). Most of the records included in this dataset belong to the class Magnoliopsida (99.58\%). There are 5 orders represented in the dataset, with Fagales (98.98\%) being the most important order. The other 4 orders (Rosales, Cupressales, Sapindales and Pinales) represent only 1.02\% of the records. In this collection, 5 families are represented: Fagaceae, Rosaceae, $\mathrm{Cu}-$ pressaceae, Pinaceae, and Sapindaceae. The most represented taxa are Quercus pyrenaica Willd. and Quercus ilex L. (81.74 and $17.24 \%$, respectively). Of the six taxa included on the dataset, three are considered threatened (Table 1).

\section{Taxonomic ranks}

Kingdom: Plantae

Phylum: Magnoliophyta, Pinophyta

Class: Magnoliopsida (Dicotyledones), Pinopsida

Table I. Conservation status and threats of the species included in the dataset.

\begin{tabular}{l|c|c|c}
\hline Scientific Name & Andalusian Red List $^{1}$ & IUCN $^{2}$ & Threat $^{3}$ \\
\hline Acer opalus subsp. granatense (Boiss.) Font Quer \& Rothm. & NT & VU & $1,2,3$ \\
\hline Quercus pyrenaica Willd. & NT & LR-cd & $1,2,4,5,6$ \\
\hline Sorbus aria Wimm. & NT & VU & $1,2,3,7$ \\
\hline
\end{tabular}

${ }^{1} 2005$ Red List of vascular flora of Andalusia (Cabezudo et al. 2005). ${ }^{2}$ IUCN category in Sierra Nevada (Blanca et al. 1998, Blanca et al. 2001, IUCN 2001, Lorite et al. 2007). ${ }^{3}$ Threats against the species (Herrera et al. 2000, Prados et al. 2000, Vivero et al. 2000, Marańón et al. 2004, Cabezudo et al. 2005, Gómez-Aparicio et al. 2005, Gómez-Aparicio et al. 2008). 1: regeneration; 2: fire; 3: overgrazing; 4: inappropriate forestry practices; 5 : changes in agriculture and agricultural practices; 6 : erosion; 7: demography. $V U$ : Vulnerable; $N T$ : Near threatened; LR-nt: $L R-c d$ : Lower Risk-Conservation Dependent. 
Order: Fagales, Pinales, Cupressales, Sapindales, Rosales

Family: Fagaceae, Pinaceae, Cupressaceae, Sapindaceae, Rosaceae

Genus: Quercus, Pinus, Juniperus, Acer, Sorbus

Species: Quercus pyrenaica, Pinus sylvestris, Juniperus communis, Acer opalus subsp. granatense, Sorbus aria, Quercus ilex

\section{Spatial coverage}

\section{General spatial coverage}

\section{Quercus pyrenaica forests}

The Pyrenean oak (Quercus pyrenaica Willd.) forests extend through south-western France and the Iberian Peninsula (Franco 1990) (Figure 2a) reaching its southern limit in north of Morocco. In the Iberian Peninsula these forests live under meso-supramediterranean and mesotemperate areas and subhumid, humid and hyperhumid ombroclimate (Rivas-Martínez et al. 2002) living on siliceous soils, or soils poor in basic ions (Vilches de la Serna 2014). Q. pyrenaica requires between 650 and 1200 $\mathrm{mm}$ of annual precipitation and a summer minimal precipitation between 100 and 200 mm (Martínez-Parras and Molero-Mesa 1982, García and Jiménez 2009), summer rainfall being a key factor in the distribution of the species (Gavilán et al. 2007, Río et al. 2007).

The forests dominated by Q. pyrenaica constitute an ecosystem included in the Annex I of the Habitat Directive (habitat code 9230: Quercus pyrenaica oak woods and Quercus robur and Quercus pyrenaica oak woods from Iberian northwestern). The conservation status of this habitat is not well known (EIONET 2014), partly due to lack of detailed ecological studies (García and Jiménez 2009).

This species reaches its southernmost European limit at Sierra Nevada mountains, where eight oak patches (2400 Has) have been identified (Figure 2b), ranging between 1100 and 2000 m a.s.l. and generally associated to major river valleys. Sierra Nevada is considered a glacial refugia for deciduous Quercus species during glaciation (Brewer et al. 2002, Olalde et al. 2002, Rodríguez-Sánchez et al. 2010) and these populations are considered as a rear edge of the habitat distribution, which is important in determining habitat responses to expected climate change (Hampe and Petit 2005).

These forests, like other vegetation types, have undergone intense human pressure (wood cutting, grazing, etc.) which has reduced their distribution area and in some cases has altered their floristic pattern (Gavilán et al. 2000, Gavilán et al. 2007).

Q. pyrenaica is considered as vulnerable in southern Spain (Vivero et al. 2000). The populations of Pyrenean oak forests at Sierra Nevada are considered relict forests (Melendo and Valle 2000, Vivero et al. 2000), undergoing intensive anthropic use in the last few decades (Camacho-Olmedo et al. 2002, Valbuena-Carabaña et al. 2010). The relict presence of this species in Sierra Nevada is related both to its genetic resil- 


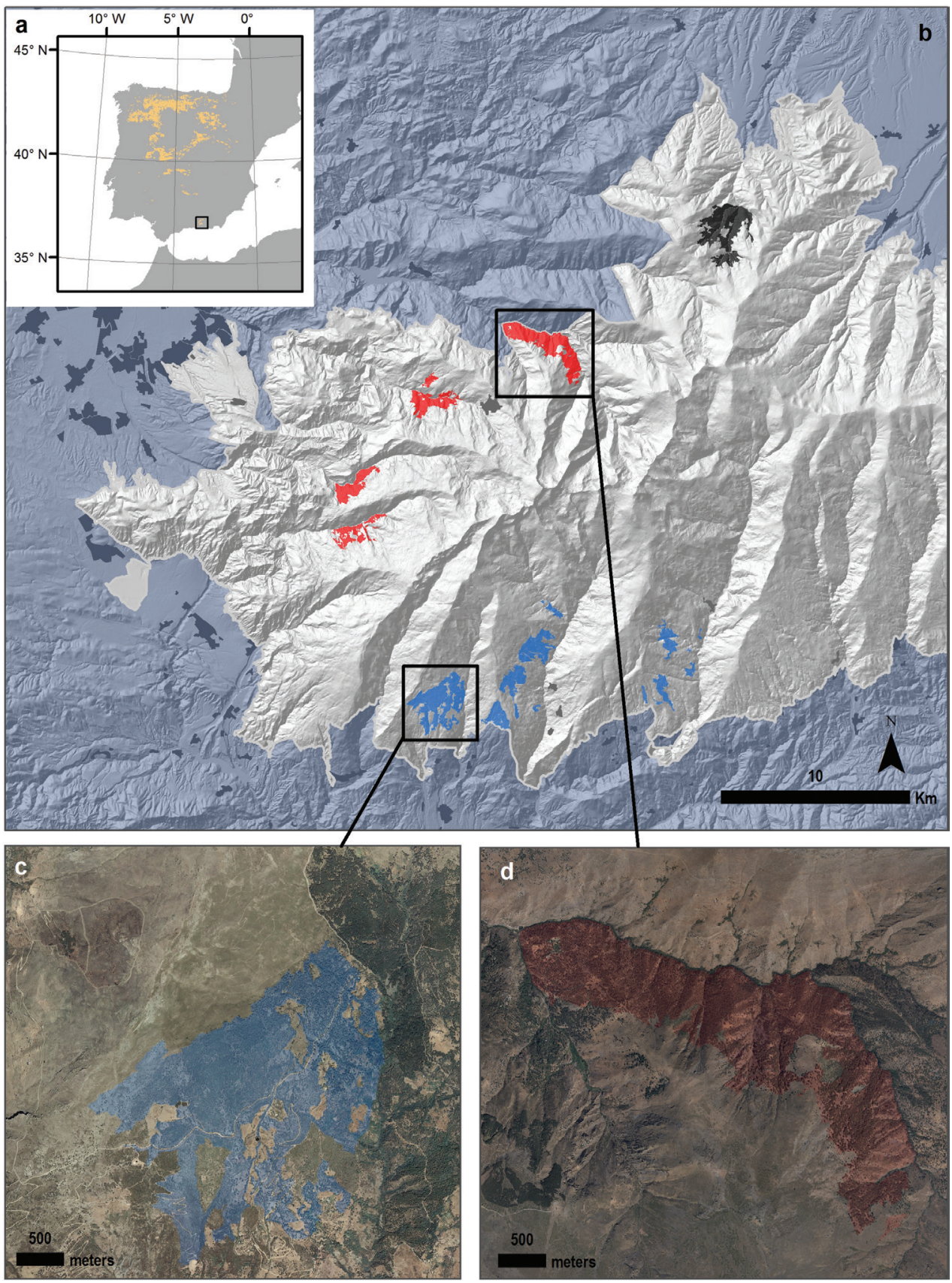

Figure 2. Distribution of Quercus pyrenaica forests in Iberian Peninsula (a). Sierra Nevada harbours eight populations of $Q$. pyrenaica clustered into three groups (different colours). We selected two study sites: Robledal de Cañar (c) and Robledal San Juan (d). Colour Orthophotography of 2009 from Regional Ministry of the Environment, Regional Government of Andalusia. 
ience as well as to its high intraspecific genetic diversity (Valbuena-Carabaña and Gil 2013). However, they are also expected to suffer the impact of climate change, due to their climate requirements (wet summers). Thus, simulations of the climate change effects on this habitat forecast a reduction in suitable habitats for Sierra Nevada (Benito et al. 2011).

\section{Coordinates}

$36^{\circ} 56^{\prime} 13.2^{\prime \prime} \mathrm{N}$ and $37^{\circ} 8^{\prime} 9.6^{\prime \prime} \mathrm{N}$ Latitude; $3^{\circ} 26^{\prime} 16.8^{\prime \prime} \mathrm{W}$ and $3^{\circ} 20^{\prime} 16.8^{\prime \prime W}$ Longitude

\section{Temporal coverage}

2012-2014

\section{Collection name}

Dataset of MIGRAME Project (Global Change, Altitudinal Range Shift and Colonization of Degraded Habitats in Mediterranean Mountains)

\section{Collection identifier}

http://www.gbif.es/ipt/resource.do?r=migrame

\section{Methods}

\section{Study extent description}

The MIGRAME dataset covers the Pyrenean oak forests (see Spatial coverage section) in Sierra Nevada mountain range (see Study area descriptions section).

\section{Sampling description}

We sampled two localities of the Pyrenean oak forests in Sierra Nevada: Robledal de Cañar and Robledal de San Juan. We selected those two sites based on previous works (Pérez-Luque 2011, Pérez-Luque et al. 2013) that clustered the populations 
of Q. pyrenaica forests based on their plant species composition and environmental features. The Robledal de Cañar site (Figure 2c) (1366-1935 m a.s.l., 3757'28.04"N, $3^{\circ} 25^{\prime} 57.1$ "W; Cánar, Granada, SE Spain) was located in the Alpujarras Region on the southern slopes of Sierra Nevada. The Robledal de San Juan (Figure 2d) (1189-1899 m a.s.l., 37²'29.63"N, 3²1'54.60"W; Güejar-Sierra, Granada, SE Spain) site was located in the northern slopes of Sierra Nevada.

The sampling design was determined by the hypothesis of the project (see Project Design description section).

\section{Altitudinal migration design}

To test our hypothesis of altitudinal migration, we sampled a total of 104 transects (Table 2) distributed along an altitudinal gradient at the two sites. We sampled two transects (at least $10 \mathrm{~m}$ apart) every $25 \mathrm{~m}$ of elevation from forest limit to treeline ecotone at both study sites. At each locality, we performed three replicates of this design (Figure 3a).

\section{Habitat colonization design}

To test the hypothesis of colonization of marginal habitats, we laid out transects in two types of marginal habitats: abandoned agricultural areas and pine plantations (Figure $3 \mathrm{~b})$. A total of 64 transects were located within the marginal habitat and on the edge between marginal habitat and Pyrenean oak forest. The number of transects inside the marginal habitat was determined by the size of the marginal habitat (Table 3).

\section{Forest samplings}

In addition to the above surveys, we conducted a survey inside $Q$. pyrenaica forests. A total of 31 transects were distributed at the two sites.

Table 2. Transect number of the Altitudinal migration design.

\begin{tabular}{c|c|c|c|c}
\hline Locality & Altitudinal gradient & \multicolumn{3}{|c}{ Transects $^{\mathbf{1}}$} \\
\hline & & $R 1$ & $R 2$ & $R 3$ \\
\hline Robledal de Cañar & $1900-2150$ & 12 & 20 & 20 \\
\hline Robledal de San Juan & $1775-2000$ & 18 & 18 & 16 \\
\hline
\end{tabular}

${ }^{1}$ For each replicate (R1 to R3) the number of transects is shown. 


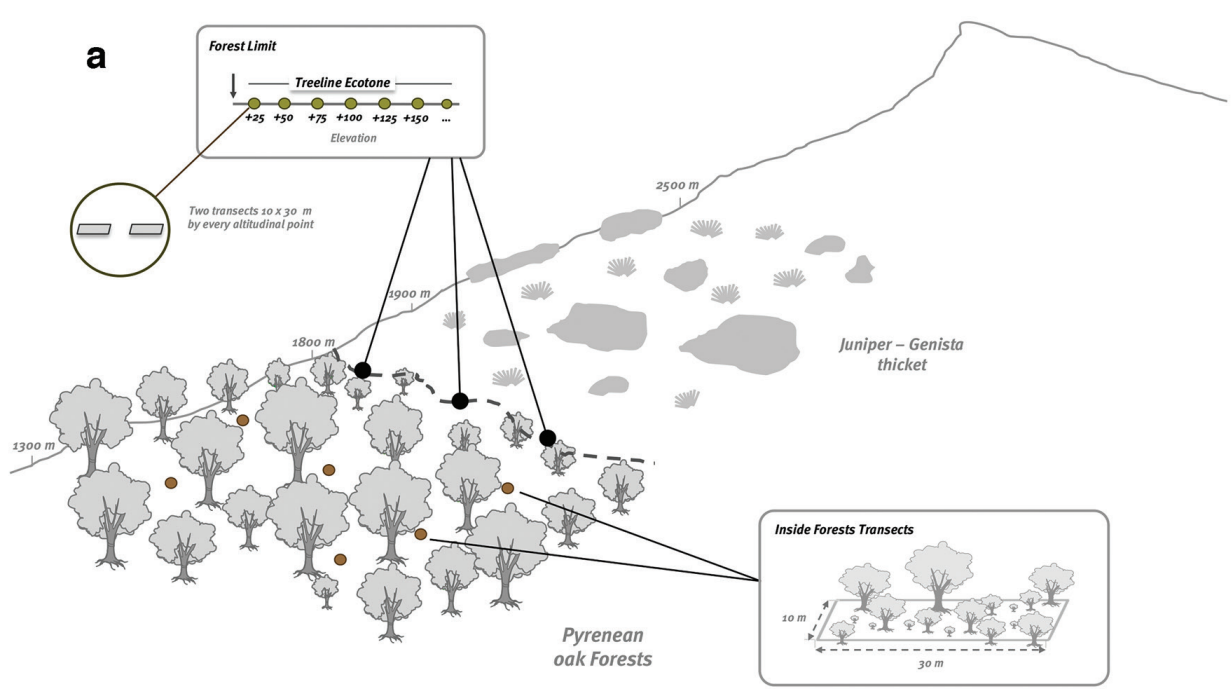

b

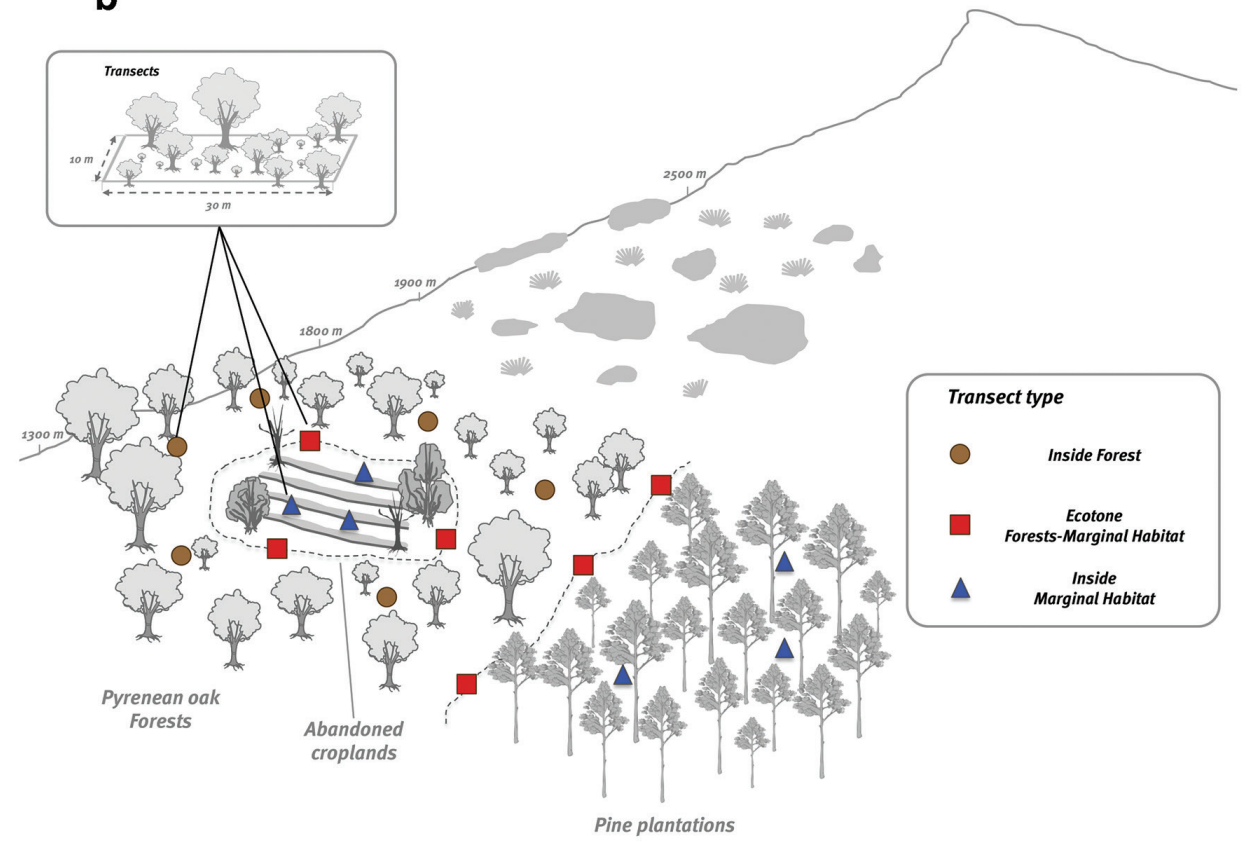

Figure 3. Sampling Design. a Altitudinal migration hypothesis. At each study site, from the forest edge to treeline ecotone, we sampled each $25 \mathrm{~m}$ of elevation $\mathbf{b}$ Colonization of marginal habitat hypothesis. Transects were located on three habitat types: Forests (brown circles), Forest Edges (red squares) and Inside Marginal Habitats (blue triangles). 
Table 3. Transects number of the Colonization of marginal habitat design.

\begin{tabular}{|c|c|c|c|c|c|}
\hline & & & & & \\
\hline Locality & Marginal habitat & Replicate & Surface (ha) & Inside & Edge \\
\hline & & $\mathrm{R} 1$ & 3.29 & 6 & 3 \\
\hline Robleddle Cañar & Abandoned Cropland & $\mathrm{R} 2$ & 5.80 & 9 & 3 \\
\hline Robledal de Canar & & R3 & 1.55 & 3 & 3 \\
\hline & Pine plantation & & 80.70 & 6 & 6 \\
\hline Robled lde Son Junn & Abondoned Cronland & $\mathrm{R} 1$ & 3.46 & 6 & 3 \\
\hline Kobledal de San Juan & ADandoned Cropiand & $\mathrm{R} 2$ & 10.36 & 13 & 3 \\
\hline
\end{tabular}

\section{Data collection}

We sampled a total of 199 linear transects of $30 \mathrm{~m} \times 10 \mathrm{~m}$ (Suppl. material 1). Within each transect, all tree species were recorded and the species identity was recorded. Diameter size and tree height were measured for all individuals. Field data were recorded using handheld PDAs. A customized application (app) (Figure 4) was built to facilitate both data collection and storage (Pérez-Pérez et al. 2013 - http://obsnev.es/noticia. html?id=4513). The data were automatically integrated into an information system using this application.

\section{Method step description}

All data were stored in a relational database (PostgreSQL) and added to the Information System of Sierra Nevada Global-Change Observatory (Figure 4) (http://obsnev. es/linaria.html - Pérez-Pérez et al. 2012; Free access upon registration). Taxonomic and spatial validations were made on this database (see Quality-control description). A custom-made SQL view of the database was performed to gather occurrence data and other variables associated with some occurrence data (diameter size and tree height of each individual).

The occurrence and measurement data were accommodated to fulfil the Darwin Core Standard (Wieczorek et al. 2009, Wieczorek et al. 2012). We used Darwin Core Archive Validator tool (http://tools.gbif.org/dwca-validator/) to check whether the dataset met Darwin Core specifications. The Integrated Publishing Toolkit (IPT v2.0.5) (Robertson et al. 2014) of the Spanish node of the Global Biodiversity Information Facility (GBIF) (http://www.gbif.es/ipt) was used both to upload the Darwin Core Archive and to fill out the metadata.

The Darwin Core elements for the occurrence data included in the dataset were: occurrenceId, modified, language, institutionCode, collectionCode, basisOfRecord, catalogNumber, recordedBy, eventDate, day, month, year, continent, country, countryCode, stateProvince, county, locality, minimumElevationInMeters, maximumEle- 


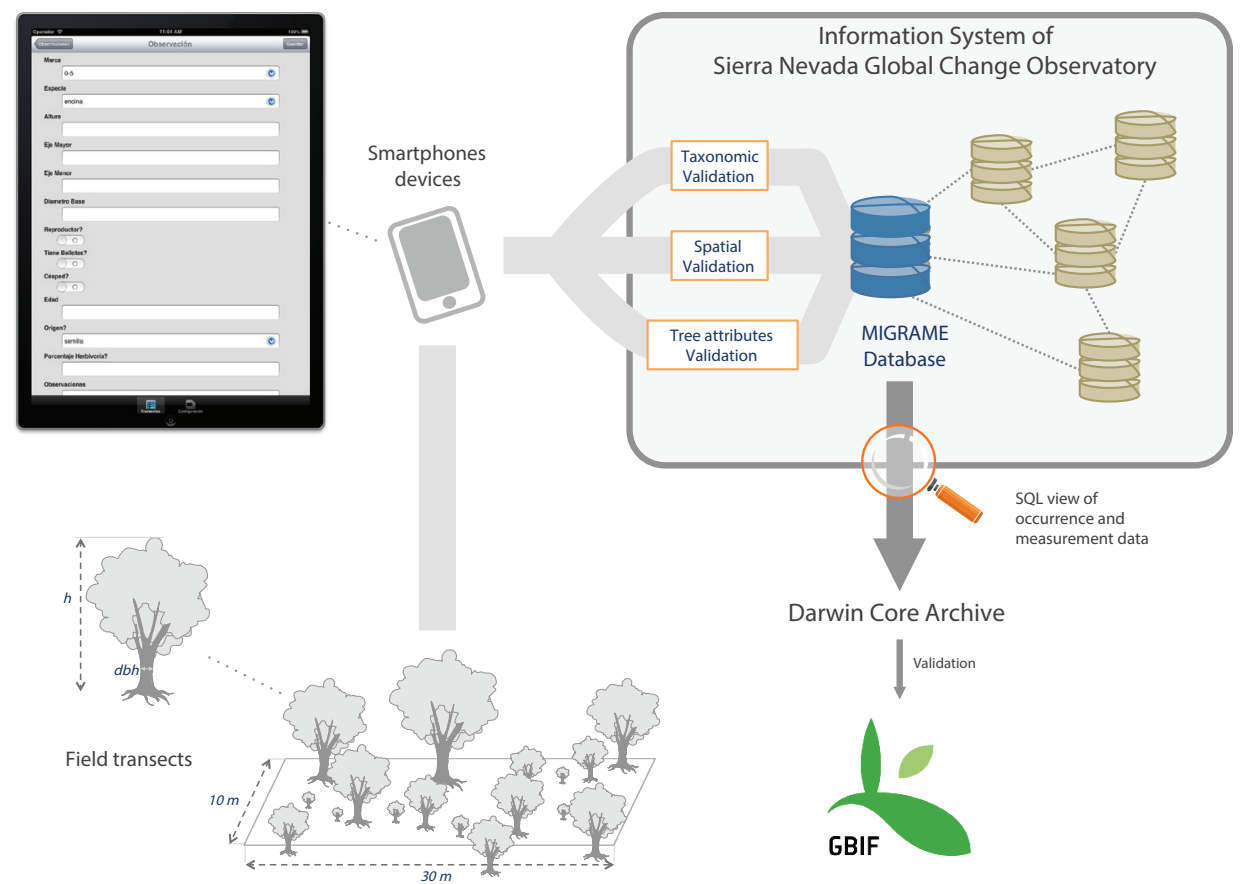

Figure 4. Diagram of integration of the dataset within Information System of Sierra Nevada Global Change Observatory (http://obsnev.es/linaria.html). Field data were recorded with Smartphone devices (see Pérez-Pérez et al. 2013). After a validation process (see Quality Control section) the occurrence and measurement data were accommodated to Darwin Core Archive and integrated into GBIF.

vationInMeters, decimalLongitude, decimalLatitude, coordinateUncertaintyinMeters, geodeticDatum, scientificName, kingdom, phylum, class, order, family, genus, specificEpithet, infraspecificEpithet, scientificNameAuthorship.

For the measurement data, the Darwin Core elements included were: occurrenceId, measurementID, measurementType, measurementValue, measurementAccuracy, measurementUnit, measurementDeterminedDate, measurementDeterminedBy, measurementMethod.

\section{Quality control description}

Transects coordinates were recorded with a handheld Garmin eTrex Vista Global Positioning System (GPS, \pm 5 m accuracy, Garmin (2007)) (WGS84 Datum). We also used colour digital orthophotographs provided by the Andalusian Cartography Institute and GIS (ArcGIS 9.2; ESRI, Redlands, California, USA) to verify the geographical coordinates of each sampling plot (Chapman and Wieczorek 2006). 
The specimens were taxonomically identified using Flora iberica (Castroviejo 1986-2005). The scientific names were checked with databases of International Plant Names Index (IPNI 2013) and Catalogue of Life/Species 2000 (Roskov et al. 2015). We also used the R package taxize (Chamberlain and Szöcs 2013, Chamberlain et al. 2014) to verify the taxonomical classification.

We also performed validation procedures (Chapman 2005a, 2005b) (geographic coordinate format, coordinates within country/provincial boundaries, absence of ASCII anomalous characters in the dataset) with DARWIN_TEST (v3.2) software (Ortega-Maqueda and Pando 2008).

\section{Dataset description}

Object name: Darwin Core Archive Dataset of MIGRAME Project (Global Change, Altitudinal Range Shift and Colonization of Degraded Habitats in Mediterranean Mountains) Character encoding: UTF-8

Format name: Darwin Core Archive format

Format version: 1.0

Distribution: http://www.gbif.es/ipt/resource.do?r=migrame

Publication date of data: $2015-05-13$

Language: English

Licenses of use: This "Dataset of MIGRAME Project (Global Change, Altitudinal Range Shift and Colonization of Degraded Habitats in Mediterranean Mountains)" is licensed under a made available under the Creative Commons Attribution Non Commercial (CC-BY-NC) 4.0 License http://creativecommons.org/licenses/by-nc/4.0/legalcode Metadata language: English

Date of metadata creation: 2015-05-13

Hierarchy level: DataSet

\section{Acknowledgements}

Funding was provided by the project MIGRAME (RNM 6734) from the Excellence Research Group Programme of the Andalusian Government. This research work was conducted in the collaborative framework of the "Sierra Nevada Global Change Observatory (LTER platform)" Project from the Environment Department of Andalusian Regional Government, the Sierra Nevada National Park and the Spanish Biodiversity Foundation ("Fundación Biodiversidad"). We thank Katia Cezón and Franciso Pando (Spanish GBIF node-CSIC) for technical support. We also thank David Nesbitt for linguistic advice. A. J. Pérez-Luque would like to thank the MICINN of the Government of Spain for the financial support (PTA 2011-6322-I). 


\section{References}

Allen CD, Breshears DD (1998) Drought-induced shift of a forest-woodland ecotone: Rapid landscape response to climate variation. Proceedings of the National Academy of Sciences 95: 14839-14842. doi: 10.1073/pnas.95.25.14839

Benito B, Lorite J, Peńas J (2011) Simulating potential effects of climatic warming on altitudinal patterns of key species in Mediterranean-alpine ecosystems. Climatic Change 108: 471-483. doi: 10.1007/s10584-010-0015-3

Benito B, Pérez-Pérez R, Zamora R, Pérez-Luque AJ (2013) Colonización de hábitats marginales y migración altitudinal del roble mediada por el arrendajo: Simulación dinámica mediante sistemas multi-agente. In: XI Congreso Nacional de la Asociación Española de Ecología Terrestre. Invitación a la ecología. Pamplona, Spain. doi: 10.7818/AEET.XICongress. 2013

Blanca G, Cueto M, Martínez-Lirola M, Molero-Mesa J (1998) Threatened vascular flora of Sierra Nevada (Southern Spain). Biological Conservation 85: 269-285. doi: 10.1016/ S0006-3207(97)00169-9

Blanca G, López Onieva M, Lorite J, Martínez Lirola MJ, Molero Mesa J, Quintas S, Ruíz Girela M, Varo MA, Vidal S (2001) Flora amenazada y endémica de Sierra Nevada. Editorial Universidad de Granada, Granada, 410 pp.

Bonet FJ, Pérez-Luque AJ, Moreno R, Zamora R (2010) Sierra Nevada Global Change Observatory. Structure and Basic Data. Environment Department (Andalusian Regional Government). University of Granada, 1-48. http://refbase.iecolab.es/files/bonet/2010/2905_ Bonet_etal2010.pdf

Brewer S, Cheddadi R, Beaulieu J de, Reille M (2002) The spread of deciduous Quercus throughout Europe since the last glacial period. Forest Ecology and Management 156: 27-48. doi: 10.1016/S0378-1127(01)00646-6

Cabezudo B, Talavera S, Blanca G, Salazar C, Cueto M, Valdés B, Hernández-Bermejo J, Herrera C, Rodríguez-Hiraldo C, Navas D (2005) Lista roja de la flora vascular de Andalucía. Consejería de Medio Ambiente. Junta de Andalucía, Sevilla, 1-126.

Camacho-Olmedo M, García-Martínez P, Jiménez-Olivencia Y, Menor-Toribio J, Paniza-Cabrera A (2002) Dinámica evolutiva del paisaje vegetal de la Alta Alpujarra granadina en la segunda mitad del s. XX. Cuadernos Geográficos 32: 25-42.

Castroviejo S (Ed.) (1986-2005) Flora iberica. Real Jardín Botánico CSIC, Madrid.

Chamberlain S, Szöcs E (2013) taxize: Taxonomic search and retrieval in R. F1000Research 2: 191. doi: 10.12688/f1000research.2-191.v2

Chamberlain S, Szöcs E, Boettiger C, Ram K, Bartomeus I, Baumgartner J (2014) taxize: Taxonomic information from around the web. R package version 0.3.0. https://github. com/ropensci/taxize

Chapman AD (2005a) Principles and methods of Data Cleaning: Primary species and speciesoccurrence data, version 1.0. Global Biodiversity Information Facility, Copenhagen, 75 pp. http://www.gbif.org/orc/?doc_id=1262

Chapman AD (2005b) Principles of Data Quality, version 1.0. Global Biodiversity Information Facility, Copenhagen, 61 pp. http://www.gbif.org/orc/?doc_id=1229 
Chapman A, Wieczorek J (2006) Guide to Best Practices for Georeferencing. Global Biodiversity Information Facility, Copenhagen. http://www.gbif.org/orc/?doc_id=1288

Doblas-Miranda E, Martínez-Vilalta J, Lloret F, Álvarez A, Ávila A, Bonet FJ, Brotons L, Castro J, Curiel Yuste J, Díaz M, Ferrandis P, García-Hurtado E, Iriondo JM, Keenan TF, Latron J, Llusia J, Loepfe L, Mayol M, Moré G, Moya D, Peńuelas J, Pons X, Poyatos R, Sardans J, Sus O, Vallejo VR, Vayreda J, Retana J (2015) Reassessing global change research priorities in Mediterranean terrestrial ecosystems: How far have we come and where do we go from here? Global Ecology and Biogeography 24: 25-43. doi: 10.1111/geb.12224

EIONET (2014) Online report on article 17 of the Habitats Directive: Conservation status of habitats and species of community interest (2001-2006). http://bd.eionet.europa.eu/ activities/Reporting/Article_17/Reports_2007/index_html [accessed 24.07.2015]

Escribano-Avila G, Sanz-Pérez V, Pías B, Virgós E, Escudero A, Valladares F (2012) Colonization of abandoned land by Juniperus thurifera is mediated by the interaction of a diverse dispersal assemblage and environmental heterogeneity. PLoS ONE 7: e46993. doi: 10.1371/journal.pone.0046993

Franco J (1990) Quercus L. In: Castroviejo A, Laínz M, López-González G, Montserrat P, Muñoz-Garmendia F, Paiva J, Villar L (Eds) Flora iberica 2. Real Jardín Botánico CSIC, Madrid, 15-36.

García I, Jiménez P (2009) 9230 Robledales de Quercus pyrenaica y robledales de Quercus robur y Quercus pyrenaica del noroeste ibérico. In: Ministerio de Medio Ambiente, y Medio Rural y Marino (Ed.) Bases Ecológicas Preliminares para la Conservación de los Tipos de Hábitat de Interés Comunitario En España, Ministerio de Medio Ambiente, y Medio Rural y Marino, Madrid, 1-66.

García RA, Cabeza M, Rahbek C, Araújo MB (2014) Multiple dimensions of climate change and their implications for biodiversity. Science 344. doi: 10.1126/science.1247579

García-Ruiz JM, López-Moreno JI, Vicente-Serrano SM, Lasanta-Martínez T, Beguería S (2011) Mediterranean water resources in a global change scenario. Earth-Science Reviews 105: 121-139. doi: 10.1016/j.earscirev.2011.01.006

Garmin (2007) Garmin eTrex vista personal navigator. Owner's manual and reference guide. https://buy.garmin.com/shop/store/manual.jsp?product=010-00630-00 [accessed 10.05.2012]

Gavilán R, Sánchez-Mata D, Vilchez B (2000) Effects of disturbance on floristic patterns of Quercus pyrenaica forests in central Spain. In: White P, Mucina L, Leps J (Eds) Vegetation science in retrospect and perspective - Proceedings 41st IAVS symposium. Opulus Press, Uppsala, 227-230.

Gavilán R, Sánchez-Mata D, Vilchez B (2007) Modeling current distribution of spanish Quercus pyrenaica forests using climatic parameters. Phytocoenologia 37: 561-581. doi: 10.1127/0340-269X/2007/0037-0561

Giorgi F (2006) Climate change hot-spots. Geophysical Research Letters 33: L08707. doi: 10.1029/2006GL025734

Giorgi F, Lionello P (2008) Climate change projections for the Mediterranean region. Global and Planetary Change 63: 90-104. doi: 10.1016/j.gloplacha.2007.09.005 
Gordo O, Sanz JJ (2010) Impact of climate change on plant phenology in Mediterranean ecosystems. Global Change Biology 16: 1082-1106. doi: 10.1111/j.1365-2486.2009.02084.x

Gottfried M, Pauli H, Futschik A, Akhalkatsi M, Barancok P, Benito Alonso JL, Coldea G, Dick J, Erschbamer B, Fernández Calzado MR, Kazakis G, Krajci J, Larsson P, Mallaun M, Michelsen O, Moiseev D, Moiseev P, Molau U, Merzouki A, Nagy L, Nakhutsrishvili G, Pedersen B, Pelino G, Puscas M, Rossi G, Stanisci A, Theurillat J-P, Tomaselli M, Villar L, Vittoz P, Vogiatzakis I, Grabherr G (2012) Continent-wide response of mountain vegetation to climate change. Nature Climate Change 2: 111-115. doi: 10.1038/nclimate1329

Gómez-Aparicio L, Pérez-Ramos IM, Mendoza I, Matías L, Quero JL, Castro J, Zamora R, Marańón T (2008) Oak seedling survival and growth along resource gradients in Mediterranean forests: Implications for regeneration in current and future environmental scenarios. Oikos 117: 1683-1699. doi: 10.1111/j.1600-0706.2008.16814.x

Gómez-Aparicio L, Zamora R, Gómez JM (2005) The regeneration status of the endangered Acer opalus subsp. granatense throughout its geographical distribution in the Iberian Peninsula. Biological Conservation 121: 195-206. doi: 10.1016/j.biocon.2004.04.019

Hampe A, Petit RJ (2005) Conserving biodiversity under climate change: The rear edge matters. Ecology Letters 8: 461-467. doi: 10.1111/j.1461-0248.2005.00739.x

Herrera C, Manzaneda A, Benavente A, Luque P, Jordano P (2000) Sorbus aria (L.) Crantz. In: Blanca G, Cabezudo B, Hernández-Bermejo J, Herrera C, Muñoz J, Valdés B (Eds) Libro rojo de la flora silvestre amenzada de Andalucía. II. Especies vulnerables. Consejería de Medio Ambiente. Junta de Andalucía, Sevilla, 337-339.

Hughes L (2000) Biological consequences of global warming: Is the signal already apparent? Trends in Ecology \& Evolution 15: 56-61. doi: 10.1016/S0169-5347(99)01764-4

IPNI (2013) The international plant names index. http://www.ipni.org [accessed 12.12.2014] IUCN (2001) IUCN Red List Categories. Prepared by the IUCN Species Survival Commission. As approved by the 51st Meeting of the IUCN Council Gland, Switzerland. IUCN, Gland, Switzerland.

Jump AS, Peńuelas J (2005) Running to stand still: Adaptation and the response of plants to rapid climate change. Ecology Letters 8: 1010-1020. doi: 10.1111/j.1461-0248.2005.00796.x

Lenoir J, Gégout JC, Marquet PA, Ruffray P de, Brisse H (2008) A significant upward shift in plant species optimum elevation during the 20th century 320: 1768-1771. doi: 10.1126/ science. 1156831

Lorite J, Navarro FB, Valle F (2007) Estimation of threatened orophytic flora and priority of its conservation in the Baetic range (S. Spain). Plant Biosystems 141: 1-14. doi: $10.1080 / 11263500601153560$

Luterbacher J, Xoplaki E, Casty C, Wanner H, Pauling A, Küttel M, Rutishauser T, Brönnimann S, Fischer E, Fleitmann D, Gonzalez-Rouco FJ, García-Herrera R, Barriendos M, Rodrigo F, Gonzalez-Hidalgo JC, Saz MA, Gimeno L, Ribera P, Brunet M, Paeth H, Rimbu N, Felis T, Jacobeit J, Dünkeloh A, Zorita E, Guiot J, Türkes M, Alcoforado MJ, Trigo R, Wheeler D, Tett S, Mann ME, Touchan R, Shindell DT, Silenzi S, Montagna P, Camuffo D, Mariotti A, Nanni T, Brunetti M, Maugeri M, Zerefos C, Zolt SD, Lionello P, Nunes MF, Rath V, Beltrami H, Garnier E, Ladurie ELR (2006) Mediterranean climate 
variability over the last centuries: A review. In: P. Lionello PM-R, Boscolo R (Eds) Mediterranean climate variability. Elsevier, 27-148.

Marañón T, Zamora R, Villar R, Zavala M, Quero J, Pérez-Ramos I, Mendoza I, Castro J (2004) Regeneration of tree species and restoration under constrasted Mediterranean habitats: Field and glasshouse experiments. International Journal of Ecology and Environmental Sciences 30: 187-196.

Martínez-Parras J, Molero-Mesa J (1982) Ecología y fitosociología de Quercus pyrenaica Willd. en la provincia Bética. Los melojares béticos y sus etapas de sustitución. Lazaroa 4: 91-104.

Matesanz S, Valladares F (2014) Ecological and evolutionary responses of Mediterranean plants to global change. Environmental and Experimental Botany 103: 53-67. doi: 10.1016/j. envexpbot.2013.09.004

McGill B (2015) Biodiversity: Land use matters. Nature 520: 38-39. doi: 10.1038/520038a

Melendo M, Valle F (2000) Estudio comparativo de los melojares nevadenses. In: Chacón J, Rosúa J (Eds) $1^{\text {a }}$ Conferencia internacional Sierra Nevada. Universidad de Granada, Granada, 463-479.

Olalde M, Herrán A, Espinel S, Goicoechea PG (2002) White oaks phylogeography in the Iberian Peninsula. Forest Ecology and Management 156: 89-102. doi: 10.1016/S03781127(01)00636-3

Ortega-Maqueda I, Pando F (2008) DARWIN_TEST v3.2: Una aplicación para la validación y el chequeo de los datos en formato Darwin Core 1.2 or Darwin Core 1.4. Unidad de Coordinación de GBIF, CSIC. Ministerio de Educación y Ciencia, Madrid, Spain. http:// www.gbif.es/Darwin_test/Darwin_test.php [accessed 12.12.2014]

O’Connor MI, Holding JM, Kappel CV, Duarte CM, Brander K, Brown CJ, Bruno JF, Buckley L, Burrows MT, Halpern BS, Kiessling W, Moore P, Pandolfi JM, Parmesan C, Poloczanska ES, Schoeman DS, Sydeman WJ, Richardson AJ (2015) Strengthening confidence in climate change impact science. Global Ecology and Biogeography 24: 64-76. doi: 10.1111/ geb. 12218

Pacifici M, Foden WB, Visconti P, Watson JEM, Butchart SHM, Kovacs KM, Scheffers BR, Hole DG, Martin TG, Akçakaya HR, Corlett RT, Huntley B, Bickford D, Carr JA, Hoffmann AA, Midgley GF, Pearce-Kelly P, Pearson RG, Williams SE, Willis SG, Young B, Rondinini C (2015) Assessing species vulnerability to climate change. Nature Climate change 5(3): 215-224. doi: 10.1038/nclimate2448

Padilla FM, Vidal B, Sánchez J, Pugnaire FI (2010) Land-use changes and carbon sequestration through the twentieth century in a Mediterranean mountain ecosystem: Implications for land management. Journal of Environmental Management 91: 2688-2695. doi: 10.1016/j.jenvman.2010.07.031

Parmesan C (2006) Ecological and evolutionary responses to recent climate change. Annual Review of Ecology, Evolution, and Systematics 37: 637-669. doi: 10.1146/annurev.ecolsys.37.091305.110100

Parmesan C, Yohe G (2003) A globally coherent fingerprint of climate change impacts across natural systems 421: 37-42. doi: 10.1038/nature01286

Pérez-Luque AJ (2011) Análisis multivariante ambiental de los melojares de Quercus pyrenaica Willd. de Sierra Nevada. Master's thesis. University of Granada, Granada, 63 pp. 
Pérez-Luque AJ, Bonet FJ, Benito B, Zamora R (2013) Caracterización ambiental de los robledales de Quercus pyrenaica Willd. de Sierra Nevada. In: XI Congreso Nacional de la Asociación Española de Ecología Terrestre. Invitación a la ecología. Pamplona, Spain. doi: 10.7818/AEET.XICongress.2013

Pérez-Pérez R, Bonet FJ, Pérez-Luque AJ, Zamora R (2012) Linaria: a set of information management tools to aid environmental decision making in Sierra Nevada (Spain) LTER site. In: Long Term Ecological Research (LTER) (Ed.) Proceedings of the 2013 LTER All Scientist Meeting: The Unique Role of the LTER Network in the Antropocene: Collaborative Science Across Scales. LTER, Estes Park - Colorado, USA.

Pérez-Pérez R, Pérez-Luque AJ, Navarro I, Bonet FJ, Zamora R (2013) Seguimiento y divulgación de procesos ecológicos mediante dispositivos móviles: Un caso práctico. In: XI Congreso Nacional de la Asociación Española de Ecología Terrestre. Invitación a la ecología. Pamplona, Spain. doi: 10.7818/AEET.XICongress.2013

Pías B, Escribano-Avila G, Virgós E, Sanz-Pérez V, Escudero A, Valladares F (2014) The colonization of abandoned land by spanish juniper: Linking biotic and abiotic factors at different spatial scales. Forest Ecology and Management 329: 186-194. doi: 10.1016/j. foreco.2014.06.021

Prados J, Vivero J, Hernández-Bermejo J (2000) Acer opalus Mill. subsp. granatense (Boiss.) Font Quer \& Rothm. In: Blanca G, Cabezudo B, Hernández-Bermejo J, Herrera C, Muñoz J, Valdés B (Eds) Libro rojo de la flora silvestre amenzada de Andalucía. II. Especies vulnerables. Consejería de Medio Ambiente. Junta de Andalucía, Sevilla, 21-23.

Rivas-Martínez S, Díaz T, Fernández-González F, Izco J, Loidi J, Lousa M, Penas A (2002) Vascular plant communities of Spain and Portugal. Addenda to the syntaxonomical checklist of 2001. Itinera Geobotanica 15: 5-922.

Río S del, Herrero L, Penas A (2007) Bioclimatic analysis of the Quercus pyrenaica forests in Spain. Phytocoenologia 37: 541-560. doi: 10.1127/0340-269X/2007/0037-0541

Robertson T, Doring M, Guralnick R, Bloom D, Wieczorek J, Braak K, Otegui J, Russell L, Desmet P (2014) The GBIF Integrated Publishing Toolkit: Facilitating the efficient publishing of biodiversity data on the internet. PLoS ONE 9: e102623. doi: 10.1371/journal. pone. 0102623

Rodríguez-Sánchez F, Hampe A, Jordano P, Arroyo J (2010) Past tree range dynamics in the Iberian Peninsula inferred through phylogeography and palaeodistribution modelling: A review. Review of Palaeobotany and Palynology 162: 507-521. doi: 10.1016/j.revpalbo.2010.03.008

Rosenzweig C, Karoly D, Vicarelli M, Neofotis P, Wu Q, Casassa G, Menzel A, Root T, Estrella N, Seguin B, Tryjanowski P, Liu C, Rawlins S, Imeson A (2008) Attributing physical and biological impacts to anthropogenic climate change. Nature 453: 353-357. doi: $10.1038 /$ nature 06937

Roskov Y, Abucay L, Orrell T, Nicolson D, Kunze T, Culham A, Bailly N, Kirk P, Bourgoin T, DeWalt R, Decock W, De Wever A (Eds) (2015) Species 2000 \& ITIS Catalogue of Life. Species 2000: Naturalis, Leiden, the Netherlands. http://www.catalogueoflife.org/col [accessed 05.02.2015] 
Rounsevell M, Reginster I, Araújo M, Carter T, Dendoncker N, Ewert F, House J, Kankaanpää S, Leemans R, Metzger M, Schmit C, Smith P, Tuck G (2006) A coherent set of future land use change scenarios for Europe. Agriculture, Ecosystems \& Environment 114: 57-68. doi: 10.1016/j.agee.2005.11.027

Sala OE, Stuart Chapin F, III, Armesto JJ, Berlow E, Bloomfield J, Dirzo R, Huber-Sanwald E, Huenneke LF, Jackson RB, Kinzig A, Leemans R, Lodge DM, Mooney HA, Oesterheld M, Poff NL, Sykes MT, Walker BH, Walker M, Wall DH (2000) Global biodiversity scenarios for the year 2100. Science 287: 1770-1774. doi: 10.1126/science.287.5459.1770

Suttle KB, Thomsen MA, Power ME (2007) Species interactions reverse grassland responses to changing climate. Science 315: 640-642. doi: 10.1126/science.1136401

Thuiller W, Albert C, Araújo MB, Berry PM, Cabeza M, Guisan A, Hickler T, Midgley GF, Paterson J, Schurr FM, Sykes MT, Zimmermann NE (2008) Predicting global change impacts on plant species' distributions: Future challenges. Perspectives in Plant Ecology, Evolution and Systematics 9: 137-152. doi: 10.1016/j.ppees.2007.09.004

Thuiller W, Lavorel S, Araújo MB, Sykes MT, Prentice IC (2005) Climate change threats to plant diversity in Europe. Proceedings of the National Academy of Sciences 102: 82458250. doi: 10.1073/pnas.0409902102

Valbuena-Carabaña M, Heredia UL de, Fuentes-Utrilla P, González-Doncel I, Gil L (2010) Historical and recent changes in the spanish forests: A socio-economic process. Review of Palaeobotany and Palynology 162: 492-506. doi: 10.1016/j.revpalbo.2009.11.003

Valbuena-Carabaña M, Gil L (2013) Genetic resilience in a historically profited root sprouting oak (Quercus pyrenaica Willd.) at its southern boundary. Tree Genetics \& Genomes 9: 1129-1142. doi: 10.1007/s11295-013-0614-z

Vilches de la Serna B (2014) Comprehensive study of Quercus pyrenaica Willd. forests at Iberian Peninsula: Indicator species, bioclimatic, and syntaxonomical characteristics. PhD thesis. Complutense University of Madrid, $194 \mathrm{pp}$.

Vivero J, Prados J, Hernández-Bermejo J (2000) Quercus pyrenaica Willd. In: Blanca G, Cabezudo B, Hernández-Bermejo J, Herrera C, Muñoz J, Valdés B (Eds) Libro rojo de la flora silvestre amenzada de Andalucía. II. Especies vulnerables. Consejería de Medio Ambiente. Junta de Andalucía, Sevilla, 303-306.

Wieczorek J, Döring M, De Giovanni R, Robertson T, Vieglais D (2009) Darwin core terms: A quick reference guide. http://rs.tdwg.org/dwc/terms/ [accessed 12.12.2014]

Wieczorek J, Bloom D, Guralnick R, Blum S, Doring M, Giovanni R, Robertson T, Vieglais D (2012) Darwin core: An evolving community-developed biodiversity data standard. PLoS ONE 7: e29715. doi: 10.1371/journal.pone.0029715

Wolkovich EM, Cook BI, Davies TJ (2014) Progress towards an interdisciplinary science of plant phenology: Building predictions across space, time and species diversity. New Phytologist 201: 1156-1162. doi: 10.1111/nph.12599

Zamora R, Pérez-Luque AJ, Benito B, Bonet FJ, Navarro I, Pérez-Pérez R, Hódar J, Matías L (2013) Cambio global, migración altitudinal y colonización de hábitats degradados en montañas mediterráneas (MIGRAME). In: XI Congreso Nacional de la Asociación Española de Ecología Terrestre. Invitación a la ecología. Pamplona, Spain. doi: 10.7818/AEET. XICongress.2013 


\section{Supplementary material I}

\section{Table S1}

Authors: Antonio Jesús Pérez-Luque, Regino Zamora, Francisco Javier Bonet, Ramón

Pérez-Pérez

Data type: Table

Explanation note: Information about transects of the project. Elevation in $\mathrm{m}$ a.s.l.. Type: $A M=$ Altitudinal migration; $F O=$ Forest; $M H=$ Marginal Habitat. Subtype: $A C-e$ : Abandoned Cropland: edge; $A C-i$ : Abandoned Cropland: inside; Pp-e: Pine plantations: edge; $P p-i$ : Pine plantations: inside; TE: Treeline Ecotone. Locality: $C A=$ Robledal de Cánar; $S J$ = Robledal de San Juan.

Copyright notice: This dataset is made available under the Open Database License (http://opendatacommons.org/licenses/odbl/1.0/). The Open Database License (ODbL) is a license agreement intended to allow users to freely share, modify, and use this Dataset while maintaining this same freedom for others, provided that the original source and author(s) are credited. 